\title{
Posicionamiento: La producción discursiva de la identidad
}

\author{
Brownyn Davies y Rom Harré \\ Traducción: César A. Cisneros Puebla
}

Publicación original: Davies, Bronwyn y Rom Harré (1990) Positioning: The Discursive Production of Selves. Journal for the Theory of Social Behaviour. 20 (1), 43-63.

\section{Introducción}

La idea de este artículo surgió de una discusión acerca de los problemas inherentes al uso del concepto de rol en el desarrollo de una psicología social de a identidad. Se explora que el concepto de posicionamiento puede usarse para facilitar el pensamiento de analistas sociales con orientación lingüística al permitir usos no contemplados por el concepto de rol. En particular, el nuevo concepto ayuda a enfocarse en los aspectos dinámicos de los encuentros, en contraste con la manera en la que el uso de "rol" sirve para enfatizar los aspectos ritualísticos, estáticos y formales. El posicionamiento debe entenderse desde el punto de vista inmanetista del lenguaje, explicado detalladamente por Harris (1982), en el cual éste existe sólo como ocasiones concretas del lenguaje en uso. La langue es un mito intelectualizante, únicamente la parole es real, sociológica y psicológicamente hablando. Esta posición se desarrolla en contraste con la tradición lingüística en la cual sintaxis, semántica y pragmatismo se utilizan en un ámbito abstracto de entidades causalmente potentes, formativas del habla real. En nuestro análisis y explicación empleamos acto de habla, indexicalidad y contexto; es decir, conceptos centrales de la etogenia o nuevo paradigma de la psicología (Harré, 1979; Harré y Secord, 1973; Davies, 1982). La teoría feminista postestructuralista tiene paralelismos interesantes con esta posición. El reconocimiento de la fuerza de "prácticas discursivas", la forma en que la gene se "posiciona" en esas prácticas y la manera en que la "subjetividad" individual se genera a través del aprendizaje y el uso de ciertas prácticas discursivas se mide con la "nueva psicosociolingüística" (Davies, 1989; Henriques et al., 1984; Potter y Wetherhall, 1988; Weedon, 1987).

\section{La visión inmanentista de las producciones humanas ordenadas}

De acuerdo con una vieja tradición, el orden de muchas producciones humanas, -conversaciones, por ejemplo- es de algún modo consecuencia de reglas y convenciones independientes de las producciones. En algunas lecturas de la escuela lingüística de Chomsky, las gramáticas transformacionales se toman como preexistentes en sus roles en los procesos psicológicos reales de producción lingüística. Vamos a llamar trascendentalismo a esta visión. En nuestro artículo asumimos un punto de vista contrario o inmanentista. Para nosotros, las reglas son formulaciones explícitas del 
orden normativo inmanente en producciones humanas concretas, tales como conversaciones reales entre individuos. Estas formulaciones son una forma especial de discurso con propósitos sociales propios. De acuerdo con el punto de vista inmanentista sólo hay conversaciones reales, pasadas y presentes. Se explican las semejanzas entre distintas conversaciones con referencia sólo hacia lo sucedido concretamente antes, y los recuerdos de ello. Este proceso origina los recursos personales y culturales para los hablantes, y de ahí obtienen elementos para construir el momento presente.

Aunque mecanismos mnemónicos artificiales como libros y manuales se entienden a menudo como evidencia de estructuras cognoscitivas preexistentes, independientes de cualquier hablante, estas últimas tienen significado exclusivamente cuando son tomadas por cualquier hablante-escucha como codificaciones a las cuales hay que poner atención. Es efectivamente en conversaciones reales ya ocurridas donde se encuentran los arquetipos de las conversaciones presentes. Recordamos lo dicho y hecho por nosotros, lo que creemos o nos dijeron que habían dicho y hecho, lo correcto y lo incorrecto. En esta visión, la gramática no se manifiesta como una potente realidad psicológica estructuradora de formas sintácticas; más bien, es un aspecto de una conversación especialista en la cual algunos individuos hablan y escriben unos a otros acerca de lo que otras personas dicen y escriben. Se pueden obtener ejemplos de este tipo de escritura en sociedades altamente cultas para utilizarlos como modelos concretos de la forma correcta de hablar. Este trabajo relaciona esa posición inmanetista con todas las teorías similares acerca de las fuentes de las producciones humanas ordenadas, en particular hacia los conjuntos de reglas sociales.

Si nos referimos al "sexismo" o a la "discriminación en contra de los ancianos" en el uso del lenguaje, estamos enfatizando ciertas conversaciones pasadas como ejemplos moralmente inaceptables de hablar y escribir. Conversaciones pasadas pueden considerarse objetables en el presente. Esto no se debe a si los hablantes en el pasado o el presente intentaron que sus palabras fueran derogatorias para las mujeres o los ancianos. Es más bien porque se puede mostrar que, como en el pasado, puede haber consecuencias negativas, aunque no malintencionadas, al usar estas formas de hablar. Ofrecemos el concepto posición como reemplazo inmanentista para un conjunto de conceptos trascendentalistas, como el de rol.

\section{La conversación como una acción conjunta para la producción de actos del habla determinados}

Puesto que el "posicionamiento" es por mucho un fenómeno conversacional debemos aclarar en qué nivel de análisis el hablar juntos va a ser tomado como conversación relevante. Consideramos a la conversación como una forma de interacción social generadora de productos sociales -relaciones interpersonales, por ejemplo-. Debemos, por tanto, seleccionar conceptos analíticos útiles para mostrar a la conversación como un grupo estructurado de actos de habla, es decir, como dichos y hechos definidos con referencia a su fuerza social (fuerza ilocucionaria). Este nivel de análisis debe ampliarse para incluir las contribuciones no verbales a la conversación. Por ejemplo, se han encontrado indicios fenomenológicamente identificables por medio de los cuales la gente puede distinguir, al sonar el teléfono, si la llamada es para ellos (Garfinkel, 1989). "Me están llamando a mí" es un concepto analítico a nivel acto del habla.

¿Vamos entonces a considerar a la conversación como una decodificación peligrosa (la que hace el escucha) de las intenciones individuales y sociales de cada hablante? La versión de Searle (1979) de 
la teoría del acto de habla de la conversación de Austin (1975) se dirige ciertamente en esa dirección, pues considera que el tipo de acto de habla sea definido por la intención social de la persona que lo emitió. Nosotros sostenemos lo contrario. Una conversación se desarrolla a través de la acción conjunta de todos los participantes mientras socialmente determinan (o intentan determinar) sus propias acciones y las ajenas. Una acción del habla puede convertirse en determinado acto de habla si se toma como tal por todos los participantes. Evoluciona y cambia al desarrollarse la conversación. Esta forma de pensar los actos de habla permite que múltiples actos de habla se completen en lo que se dice y que todo acto de habla en lo que se escucha sea esencialmente anulable (cf. Muhlhausler y Harré, 1990; Pearce, 1989). Al desarrollar nuestra visión de posicionamiento propondremos una interrelación productiva entre posición y fuerza ilocucionaria. Se mostrará que el significado social de lo dicho depende del posicionamiento de los interlocutores, lo cual es en sí mismo un producto de la fuerza social de una acción de conversación que se "tiene". Usaremos, además, el término práctica discursiva para todas las formas activas de producción de realidades sociales y psicológicas.

En este contexto, un discurso debe ser entendido como el uso institucionalizado del lenguaje y de sistemas simbólicos semejantes al mismo. La institucionalización puede ocurrir en los niveles disciplinario, político, cultural y de grupos pequeños. Puede haber también discursos desarrollados alrededor de un tema específico, tales como el género o la clase. Los discursos pueden competir unos con otros o buen crear versiones de realidad distintas e incompatibles. Conocer algo significa conocerlo en términos de uno o más discursos. Al respecto, Frazer (1990) expresa acerca de las chicas adolescentes entrevistadas por ella: "la comprensión y experiencia de 'los actores' con respecto a su identidad social, el mundo social y su lugar en el mismo, se construye discursivamente. Para las chicas, la experiencia de género, raza y clase; es decir, su identidad personal-social, puede sólo expresarse y entenderse a través de las categorías disponibles para ellas en el discurso".

En este sentido, en nuestra teoría social "el discurso" tiene un rol similar al "esquema conceptual" de la filosofía contemporánea de la ciencia. Es decir, consideramos cómo ambos llegan a determinarse. Proponemos, sin embargo, una distinción entre los dos términos. Los esquemas conceptuales son repertorios estáticos localizados primordialmente en la mente de cada ser pensante o investigador individual y son casi una posesión personal, mientras el discurso es un proceso público polifacético a través del cual los significados se obtienen progresiva y dinámicamente.

Un acierto importante del paradigma de investigación postestructuralista, al cual nos referimos antes, es el reconocimiento de la fuerza constitutiva del discurso y de las prácticas discursivas, en particular mientras que acepta la capacidad de la gente para elegir en relación a esas prácticas. La fuerza constitutiva de cada práctica discursiva, creemos, se encuentra en la variedad de posiciones del sujeto. Una posición del sujeto incorpora un repertorio conceptual y la correspondiente ubicación en las estructuras de derechos para quienes usan ese repertorio. Una vez que se hace propia una posición particular, una persona inevitablemente percibe el mundo desde el punto de vista de esa posición privilegiada y en términos de imágenes particulares, metáforas, argumentos y conceptos relevantes dentro de la misma. La oportunidad nocional se encuentra inevitablemente incluida porque hay muchas y contradictorias prácticas discursivas en las cuales una persona podría participar. Incluso los participante en este proceso son también producto de las prácticas discursivas.

Un individuo emerge de los procesos de interacción social no como un producto final relativamente completo, sino como uno que se constituye y reconstituye a través de las variadas prácticas discursivas en las cuales participa. De este modo, uno es siempre una pregunta abierta con una respuesta cambiante que depende de las posiciones disponibles entre las prácticas discursivas 
propias y ajenas; en esas prácticas se encuentran las historias a través de las cuales entendemos nuestras vidas y las de otros. Las historias se localizan en varios discursos diferentes; de esta forma, varían notablemente en términos del lenguaje usado, los conceptos, los temas y los juicios morales relevantes y la posición del sujeto correspondiente. De esta manera, el postestructuralismo se convierte en narratología.

Intentamos que la noción de posicionamiento sea una contribución al entendimiento de la persona. La psicología de la persona ha estado plagada por la ambigüedad del concepto de identidad, el cual ha jugado un papel importante en el discurso psicológico de la persona. La misma pregunta "¿quién soy yo?" es ambigua. Los seres humanos se caracterizan tanto por la identidad continua como por la diversidad personal discontinua. Así, la misma persona es posicionada en varias formas en una conversación. Al estar posicionada de distintas maneras, la misma persona experimenta y muestra una multiplicidad de identidades. Aunque no nos interesa la identidad personal en este artículo, la consideramos como producto de prácticas discursivas tal como lo es, también, la identidad múltiple que deseamos investigar (Harré, 1983; Muhlhausler y Harré, 1990).

\section{Las multiplicidades de la identidad}

Nuestra adquisición o desarrollo de nuestro propio ser y de cómo el mundo se interpreta desde la perspectiva de nuestra identidad implica los procesos siguientes:

1. El aprendizaje de las categorías que incluyen a algunas personas y excluyen a otras, por ejemplo: masculino/femenino, padre/hija.

2. La participación en prácticas discursivas diferentes a través de las cuales los significados se asignan a esas categorías. Estas últimas incluyen los argumentos para elaborar las diferentes posiciones de sujeto.

3. El posicionamiento de la identidad en términos de categorías y argumentos. Esto involucra posicionarse a sí mismo imaginariamente como si uno perteneciera a una categoría y no a otra (por ejemplo, como una chica y no como un muchacho, o como una buena chica y no como una chica mala).

4. El reconocimiento de uno mismo como portador de las características que lo ubican como miembro de varias subclases de categorías dicotómicas y no de otras; es decir, del desarrollo de un significado de uno mismo como perteneciendo al mundo en ciertas formas y viendo el mundo desde esa posición. Este reconocimiento implica un compromiso emocional con la categoría de pertenencia y el desarrollo de un sistema moral organizado alrededor de la pertenencia.

5. Estos cuatro procesos surgen en relación con una teoría de la identidad que cobra cuerpo en la gramática del pronombre en la cual una persona se entiende a sí misma como históricamente continua y unitaria. Experimentar las posiciones contradictorias como problemáticas, como algo que debe remediarse, surge de esta característica general de la forma en que la persona se hace en nuestra sociedad. Dentro de la teoría postestructuralista del feminismo se ha enfocado la experiencia de contradicciones como elemento importante para entender el significado de ser persona con género. Tales contradicciones no definen a la gente como distinta; es precisamente el hecho de experimentarse a sí mismo como contradictorio lo que provee la dinámica para el entendimiento (Haug, 1987). Deseamos defender la adopción de "posición" como la expresión apropiada para hablar de la producción discursiva inmersa en una diversidad de identidades que la perspectiva efímera de George Herbert Mead solemnemente llamó "mis" al referirse a las interacciones conversacionales. 


\section{El posicionamiento y sus dinámicas}

Smith (1988: XXXV) introduce el concepto de posicionamiento mediante la distinción entre "una persona" como agente individual y "el sujeto". Con la segunda expresión se refiere a "la serie o conglomerado de posiciones, de posiciones de sujeto, provisionales y no necesariamente indesarmables, en que una persona es momentáneamente puesta por los discursos y el mundo donde habita". Al hablar y actuar desde una posición, la gente trae a ese contexto particular su historia como un ser subjetivo; esa historia es la de alguien que ha estado en posiciones múltiples y ha participado en diferentes formas de discurso. La autorreflexión debería mostrar claramente que tal ser no se encuentra inevitablemente atrapado en la posición de sujeto de la narrativa particular y de las prácticas discursivas relacionadas que tal vez parecen indicar.

El posicionamiento, como lo usaremos, es el proceso discursivo donde las identidades se localizan en conversaciones en las que participantes, observable y subjetivamente coherentes, conjuntamente producen argumentos. Puede haber posicionamiento interactivo cuando lo dicho por una persona posiciona a otra. Y puede haber posicionamiento reflexivo cuando uno se posiciona a sí mismo. Sin embargo, sería un error asumir que, en cualquier caso, el posicionamiento sea necesariamente intencional. Uno vive su vida en términos de su individualidad personal, independientemente de quién se la haya creado.

Tomando la conversación como punto de partida, procederemos a asumir que cada conversación es una discusión de un tema y llevarla a cabo, ya sea explícita o implícitamente, constituye una o más historias personales -cuya fuerza la determinan los participantes por medio del orden local expresivoy hacia ellas se orientan los participantes. La misma anécdota puede constituir una manifestación de orgullo legítimo o parecer jactanciosa dependiendo de las convenciones expresivas. En cualquiera de las interpretaciones, la anécdota se convierte en un fragmento de la autobiografía. La gente será orillada entonces a estructurar las conversaciones para que desplieguen dos modos de organización: la "lógica" ostensible del tema y los argumentos contenidos en los trozos de autobiografías pertenecientes a los participantes. Las posiciones se identifican en parte por la extracción de aspectos autobiográficos de una conversación en los cuales es posible encontrar la forma usada por cada conversante para concebirse a sí mismo y a los otros participantes.

Al contar un fragmento de su autobiografía, un hablante asigna partes y personajes en los episodios descritos, tanto a sí mismo como a otras personas, incluyendo a quienes están tomando parte en la conversación. En este sentido, la estructura de una anécdota que sirve como fragmento de una autobiografía no es diferente de un cuento de hadas o de cualquier otra obra de ficción. Al dar a la gente partes en una historia, implícita o explícitamente, un hablante hace disponible una posición de sujeto que el otro hablante en el curso normal de acontecimientos tomará. En ese momento una persona "ha sido posicionada" por otro hablante. La interconexión entre posicionamiento y hacer determinada la fuerza ilocucionaria de los actos del habla puede también incluir la creación de otros posicionamiento debidos a un segundo hablante. Al responder a una expresión considerada como "condolencia", un segundo hablante se posiciona a sí mismo como, digamos, acongojado. El primer hablante pudo no haber tenido esa intención, es decir, pudo no haber querido ser posicionado como alguien que ofrece condolencias en tal ocasión.

Cuando un hablante se posiciona a sí mismo y posiciona a otro en su habla, deben tomarse en cuenta las siguientes dimensiones: 
1. Las palabras elegidas por el hablante inevitablemente contienen imágenes y metáforas que asumen e invocan la manera de ser de los participantes involucrados.

2. Los participantes pueden no estar conscientes de sus suposiciones ni del poder de las imágenes para invocar formas particulares de ser y pueden simplemente considerar sus palabras como "las cosas que uno dice" en tal ocasión. Pero al clasificar a ese momento como "tal ocasión", y asignarle palabras apropiadas, precisamente se le dio características de "tal ocasión".

3. La forma en que "tal ocasión" se considera por los participantes, puede variar de uno a otro. Compromisos sociales y morales, la clase de persona que uno piensa es, la actitud propia hacia otros hablantes, la disponibilidad de discursos alternativos al propuesto por el primer hablante (y particularmente de discursos con una crítica al hablante inicial) son todos determinados por cómo la locución del hablante inicial sea percibida. Esto se aplica también para cualquier locución subsecuente, pues la suposición hecha por los participantes es que los hablantes subsecuentes no se salgan del discurso impuesto por el primer participante de la conversación.

4. Las posiciones creadas para uno mismo y para el otro no son parte de una autobiografía lineal y no contradictoria (puesto que las autobiografías se encuentran en su forma escrita), sino más bien los fragmentos acumulativos de una autobiografía vívida.

5. Las posiciones pueden ser vistas por uno y otro de los participantes en términos de 'roles' conocidos (reales y metafóricos), o en términos de personajes conocidos en argumentos compartidos, o pueden ser mucho más efímeras e involucrar cambios en el poder, el acceso o el bloqueo de acceso a ciertas características de pretendida o deseada identidad, etcétera.

Para entender el concepto de posicionamiento, como deseamos usarlo, pensemos en alguien que escucha o lee una historia. Existe una narrativa, digamos Ana Karenina, que incorpora un desarrollo conjunto de diferentes argumentos. Cada argumento se organiza alrededor de varios polos, como acontecimientos, personajes y dilemas morales. Nuestro interés se enfoca en el conjunto de personajes (por ejemplo, Ana Karenina, Vronsky, Levin y Kitty). Los argumentos en la narrativa describen fragmentos de vidas. Que haya un grupo de personajes desde cuyos puntos de vista imaginados los acontecimientos descritos en la narrativa serán diferentes, abre la posibilidad para múltiples interpretaciones. Cualquier lector puede, por una u otra razón, posicionarse a sí mismo o ser posicionado fuera de la historia. Tal posicionamiento puede ser creado por la percepción del lector hacia el narrador y/o autor o bien puede ser creado por la representación que el lector tiene de los personajes

Si transferimos este sistema conceptual a nuestro contexto de episodios de interacción humana, llegamos a la siguiente analogía: en una conversación se crea un desarrollo entretejido de varios argumentos; éstos se organizan a través de la conversación y alrededor de varios polos, como acontecimientos, personajes y dilemas morales. Los estereotipos culturales como enfermera/paciente, director/orquesta, madre/hijo pueden ser utilizados como recursos. Es importante recordar que los recursos culturales pueden ser entendidos de manera diferente por gente distinta.

Las fuerzas ilocucionarias en las contribuciones de cada hablante en ocasiones concretas de conversación pueden tener la misma multiplicidad de los estereotipos culturales disponibles tal cual son entendidas por cada hablante. Una conversación será univocal sólo si los hablantes adoptan varias posiciones complementarias de sujeto, organizadas alrededor de la interpretación compartida de los lugares conversacionales relevantes. Incluso entonces, el hecho de que la conversación sea vista desde dos posiciones diferentes, pero complementarias, va en contra de cualquier suposición simplista de que existe un entendimiento compartido.

Un hablante puede posicionar a otros mediante un argumento que incorpore una interpretación de estereotipos culturales hacia los cuales se les "invita" a conformarse. En realidad, se les requiere 
conformarse si van a continuar la conversación para contribuir con el argumento del primer hablante. Por supuesto, ellos -por cualquier razón- pueden no hacerlo. Quizá porque no entienden el argumento, o deseen referirse a sus propios argumentos. Algunas veces no contribuirán porque no entiendan el argumento; incluso pueden desentenderse del primer hablante como muestra de rebeldía. Por otra parte, tal vez decidan conformarse porque no se definen a sí mismos como individuos capaces de elegir, o se sienten enojados, oprimidos u ofendidos por alguna combinación de los elementos anteriores.

La misma oración puede ser usada para realizar distintos actos de habla, como lo ilustraremos en nuestro análisis de una conversación real. El acto de habla particular dependerá en parte de la determinación del argumento por parte de los hablantes. Además, varias conversaciones pueden llevarse a cabo simultáneamente. También, algún hablante puede no tener acceso a una conversación por haber sido creada por otro u otros, pero puede contribuir con alguna de las oraciones que sirvan como base para los actos de habla creados por otros (Pearce y Cronen, 1981). Cualquier versión de un acto determinado de habla estará siempre abierta a negociación adicional para especificar el acto real (en caso de que éste exista).

Para ilustrar el uso del concepto de "posicionamiento" en conversaciones reales describiremos un acontecimiento de conversación donde un hablante posicionó a otro. El significado de posicionamiento para cada conversante depende del punto de vista considerado para la conversación. Nuestro ejemplo se basará en el caso donde un atributo digamos, la impotencia, se tomó como importante en vez de normal y tipificado. Para la psicología social el concepto de posicionamiento sirve para dirigir nuestra atención a un proceso por medio del cual ciertas series de consecuencias, intencionales o no, son puestas en movimiento. Pero estas consecuencias resultan solamente si las consideramos en la determinación, para ciertos individuos, de los actos de posicionamiento. Si alguien, digamos $\mathrm{A}$, ha sido posicionado como impotente, debemos ser capaces de explicar cómo esa posición es "considerada" por A: es decir, de dónde se deriva la percepción de impotencia asignada a A. ¿Cuáles suposiciones se apilan alrededor de un solo atributo, digamos impotencia, para ser considerados como válidos en el caso de A? Llamaremos a esto una extensión de significación de la actitud.

Para propósitos analíticos proponemos dos tipos de extensión:

\section{Extensión indéxica}

Para algunas personas, un atributo impuesto a una posición es interpretado -y las consecuencias de tal posicionamiento son vistas- en términos de significados indéxicos desarrollados a través de experiencias pasadas. "Impotencia", por ejemplo, puede ser entendida en términos de lo experimentado en ocasiones pasadas cuando una persona se consideró inútil. Con respecto a este atributo particular, las mujeres en sociedades industriales tienden a hacer tales extensiones del significado del concepto. Cuando se habla de poder, sin embargo, las mujeres necesitan acudir a una tipificación, digamos madre, para saber el significado. Por tanto, siguiendo este razonamiento, los hombres de razas o clases oprimidas pueden ser posicionados como impotentes, indéxicamente hablando, a la luz de sus experiencias particulares de haber sido despojados de la oportunidad de elegir o hacer algo.

\section{Extensión de tipificación}


La extensión de significación de un acto inicial correspondiente a una posición referida a un atributo singular surge en otros casos con el acoplamiento de ese atributo a un conglomerado de atributos culturalmente establecidos, los cuales son usados por el posicionamiento. Siendo ese el caso, una persona revisa metafóricamente su experiencia pasada para interpretar su posición presente (independientemente de si la acepta o rechaza) hasta que encuentre el archivo de la ocasión tipificada, como en el caso de "enfermera/paciente".

En ambas formas de extensión, el argumento en que la persona se considera inmersa es un elemento crítico para establecer el significado de la locución analizada.

\section{Esquemas analíticos alternativos}

El modelo dramatúrgico clásico ha considerado al rol como la base determinante de la acción. Con frecuencia, el drama tradicional ha servido como modelo ubicuo aunque ha habido intentos para integrar "el teatro improvisado" a los modelos de la psicología social (Coppierters, 1981). En el modelo dramatúrgico los individuos son considerados como actores con varias líneas ya escritas y sus roles son determinados por la obra de teatro representada. En una escena específica, tampoco tienen mucha oportunidad de salirse de sus roles. Han aprendido a llenar un rol particular a través de la observación de otros en la misma situación y eso los determina. El posicionamiento y la posición del sujeto, por el contrario, nos permiten elegir la posición de sujeto, localizarnos en una conversación de acuerdo con formas narrativas familiares y traer a esas narrativas nuestras historias subjetivas propias a través de las cuales hemos aprendido metáforas, personajes y argumento. Por ejemplo, consideremos el rol de madre., Todos "saben" lo que es, y cualquier persona en ese rol o en relación con alguien en ese rol, está consciente de las múltiples expectativas y obligaciones implicadas por el mismo. Puede haber variaciones del tema, tales como "madre judía", pero ésta es simplemente una madre realizando su rol dentro de las exigencias adicionales en la "cultura judía". Cualquiera tiene percepciones personales y conjuntos de emociones conectados a la idea de madre, desarrollados de la experiencia de convivir con nuestra madre. El concepto particular de madre desarrollado por alguien que algún día se convertiría en una, será diferente al mantenido por una persona sin posibilidades de convertirse en tal. Nuestro posicionamiento -debido a otros y a nosotros mismoscon respecto a "madre", y las narrativas obtenidas de nuestra vivencia con relación a madres particulares nos hacen traer a cada nuevo encuentro con alguien posicionado como madre una historia subjetiva con sus emociones y creencias concomitantes, así como también un conocimiento de estructuras sociales (incluyendo a los roles) con sus derechos, obligaciones y expectativas inherentes.

Cualquier narrativa desarrollada conjuntamente con otros trae un conocimiento de estructuras sociales y de roles reconociblemente dados a la gente dentro de esas estructuras. Las estructuras sociales son coercitivas al grado de que para ser reconocidos y aceptados como personas, debemos operar dentro de sus términos. El concepto de persona traído a cualquier acción incluye no solamente ese conocimiento de estructuras externas y de expectativas sino también la responsabilidad hacia nuestras líneas, la múltiple producción de las mismas y nuestra contribución para darle forma a la obra de teatro. De este modo, somos el agente (productor/director), el autor y el actor; los otros participantes son coautores y coproductores del drama. Pero también somos el público numeroso presente ante una obra de teatro y que trae a ella las interpretaciones múltiples y a veces contradictorias basadas en sus propias emociones, su propia interpretación de la situación y su propio 
posicionamiento imaginativo de cómo se percibe en la situación. Cada uno de estos elementos será mediado por las historias subjetivas propias. Finalmente, las narrativas vívidas pueden cambiar a los participantes la dirección y el significado en formas enteramente sorprendentes, al grado de que la metáfora de obra preestructurada empieza a perder conveniencia como una imagen viable para explicar las acciones en la interacción mutua. Si queremos entender cómo la gente en realidad interactúa en la vida diaria, necesitamos la metáfora de una narrativa en desarrollo, en la cual estemos constituidos en una u otra posición dentro del curso de una historia, o incluso llegar a estar en posiciones múltiples o contradictorias, o poder negociar una posición nueva mediante "el rechazo" de la posición que se nos ha proporcionado. Con tal metáfora podemos explicar el significado de "negarse" a aceptar la naturaleza del discurso de una conversación particular.

En nuestro marco, lo más cercano -conceptualmente hablando- a rol, es la posición de sujeto. Una posición de sujeto se logra a través del discurso. En el discurso del amor romántico, por ejemplo, hay dos grandes posiciones de sujeto complementarias logradas por el héroe o príncipe con la capacidad para obrar y quien normalmente realiza una tarea heroica, y la heroína o princesa que con frecuencia es víctima de las circunstancias y confía en su príncipe para su salvación (Brownstein, 1984; Zipes, 1986). En la vida cotidiana, si dos personas experimentan alguna versión de la narrativa del amor romántico pueden ubicarse uno y otro en la posición complementaria del sujeto lograda en el discurso del amor romántico. En otras palabras, se involucran en las prácticas discursivas a través de las cuales el amor romántico se convierte en narrativa viviente.

En obras tardías de Goffman (1974 y 1981) una terminología diferente aparece cuando varía el rumbo del modelo dramatúrgico presente en sus trabajos tempranos. El interés en el rol ubicuo de la conversación en la creación y sostenimiento de la interacción social lo llevó a desarrollar conceptos analíticos para entender las propiedades del modelo En un primer intento desarrolló la idea de marco. No fue ésta una concepción feliz, como veremos enseguida. Asegura que marcos y esquemas son la misma cosa:

Los marcos varían en grado de organización. Algunos son presentables como un sistema de entidades, postulados y reglas; otros en realidad parecen no tener una forma particularmente articulada... (Goffman, 1974: 21).

La intención del analista es aislar los marcos básicos (marcos primarios) "para poder interpretar los acontecimientos". La tarea se torna difícil, pues mientras una cosa puede aparecer en desarrollo, algo más está sucediendo; por ejemplo, una anécdota autobiográfica puede manifestarse como un chiste, una boda puede estar en una obra de teatro, etc.

Para entender los sucesos de una obra el público usa el marco primario; sin embargo, éste no tiene las consecuencias usuales (o efectos perlocucionarios). Goffman llamó al uso del marco primario en teatro un "cambio de clave", en deliberada analogía con la música. El cambio de clave involucra "una transformación sistemática a través de elementos con significado de acuerdo con un esquema de interpretación", de los cuales los participantes son conscientes. Los marcos son, como los roles, dados en un sistema cultural y las ocasiones de su uso, tanto en esta clave como en la otra, son proporcionados socialmente; por ejemplo, se llama teatro a cierto campo. De esta forma el concepto dinámico de posicionarse uno mismo en un discurso no se reduce a adoptar un marco, aunque un marco puede ser muy bien una posición, ni tampoco se reduce a un cambio de clave, aunque el mismo hecho de posicionarse lo implique. 
Su idea posterior de "balance" ${ }^{11}$ es más prometedora como una alternativa para el posicionamiento Su metáfora es doble. Ganamos o perdemos nuestro "balance" en conversaciones, grupos sociales, etcétera, de igual manera que lo ganamos o perdemos en una ladera lodosa. En la segunda capa de la metáfora, podemos cambiar nuestro balance en las conversaciones. La propia explicación de Goffman para esta nueva noción es bastante vaga, pues se basa en otras ideas indefinidas. "Cambio de balance" se refiere a las ocasiones cuando la alineación o el grupo, o la opinión, o la postura, o la identidad personal que se proyecta de "los participantes", son lo importante. "Un cambio de balance implica un cambio en la alineación hacia nosotros mismos y hacia los demás y está presente en la manera de manejar la producción y la recepción de una locución" (Goffman, 1981: 128). De esta manera, la alineación emerge enfatizada desde estas afirmaciones. Pero la claridad de la idea se ve truncada cuando Goffman une "balance" con su trabajo anterior y con el concepto vago de marco: "un cambio en nuestro balance es otra manera de hablar acerca de un cambio en nuestro marco de acontecimientos". Pero si consultamos a Goffman (1974) un marco es simplemente un conjunto de definiciones operativas del tipo Burke ${ }^{2}$, en las cuales escena, actor y acción se especifican, esencialmente, en una versión de análisis de rol.

Pero regresemos a balance. En el análisis de Goffman el hablante llena tres roles de habla: el de "animador", quien habla, el de "autor", responsable del texto; y el de "director", "cuya posición -es decir, donde el hablante está situado- se establece por las palabras habladas, alguien cuyas creencias han sido dichas, alguien comprometido con lo dicho por las palabras" (Goffman, 1981: 144). Esta es la base del formato de producción de la locución. En muchas ocasiones, animador, autor y director son una y la misma persona. Complejidades similares suceden a los escuchas. Hay siempre una estructura de participación, incluyendo diferenciaciones de "receptores oficiales" cercanos al hablante, los que escuchan por casualidad, etcétera.

Pasando ahora a la alineación y relacionándola con los formatos de producción y con los marcos de participación, aun nos falta una referencia al significado de clave. Tannen nos dice (en comunicación personal) que alineación es una noción relacional pero, hasta donde podemos juzgar, alineación son las concepciones de los hablantes, donde se une la concepción que el hablante tiene del escucha. De manera similar y, de alguna forma recíprocamente, siempre habrá un par de concepciones del escucha hacia las personas incluidas en el habla. Una conversación real cambiará, probablemente de manera imperfecta, estas creencias a relaciones reales entre los participantes. Esto no podría ser más contrastante con nuestra concepción de posicionamiento, pues da por hecho la existencia de la alineación y la considera anterior y formativa del habla, en vez de que las alineaciones son relaciones reales producidas conjuntamente en el mismo acto de conversación. Incluso en su trabajo posterior, Goffman no escapó a las restricciones de la teoría del rol. Marcos y esquemas son trascendentes para la acción y operan como mecanismos (o herramientas) preexistentes empleados para crear conversaciones. Para nosotros, la totalidad del "aparato" debe ser inmanente, reproducida momento a momento en la acción conversacional y llevada a cabo en el tiempo, no como esquema abstracto, sino como comprensiones actuales de las conversaciones pasadas y presentes.

${ }^{1}$ ( $N$ del T) Se ha traducido footing por balance a fin de mantener la imagen de movimiento que la obra de Goffman merece tener.

2 ( $\mathrm{N}$ del T) Expresión referida al conservador irlandés Edmund Burke (1729-1797), al parecer para referir un contrasentido, como en "usar un medio Burkeano para conseguir un fin no Burkeano"). 


\section{Una narrativa vivida y su análisis usando el concepto de posicionamiento}

La mejor manera de recomendar nuestra proposición es demostrar su poder analítico en un ejemplo.

Sano y Enferma participan en nuestra historia. Ambos asisten a una conferencia. Es un día de invierno en una ciudad extraña y necesitan medicina para Enferma. Un viento con temperatura bajo cero sopla en la calle. Enferma sugiere que pregunten, en vez de ir por su cuenta buscando la farmacia. Sano, como se espera de alguien con buena salud, acompañado de Enferma, se mete en las tiendas y pregunta. Después de algún tiempo deciden suspender la búsqueda, pues no hay una farmacia en los alrededores. Sano dice entonces "Siento haberte traído conmigo todo este tiempo cuando sé que no estás en las mejores condiciones". Esto sorprende a Enferma, quien replica: "Tú no me trajiste, yo decidí venir contigo". Esta repuesta desconcierta a Sano.

Sano y Enferma ofrecieron distintas explicaciones a esta situación. Las diferencias son ilustrativas del uso del concepto de posicionamiento e instructivas por sí mismas pues revelan un tercer nivel de conceptos más allá de la fuerza ilocucionaria y del posicionamiento, digamos, órdenes morales. El debate subsecuente entre nuestros protagonistas continuó de la siguiente manera:

Sano dice sentirse responsable y Enferma replica que no desea hacerlo responsable de la situación, pues esto la posiciona como alguien inútil y, por tanto, incapaz de tomar decisiones acerca de su propio bienestar. Después debaten si una persona, al tomar una responsabilidad, se la quita a la otra. Para Sano, la red de obligaciones es importantísima. Al principio no comprende cómo el cumplimiento de una obligación por parte de alguien sano, al hacerse cargo de un enfermo, pudiera constituirse como una amenaza a la libertad de este último. Enferma rechaza la idea de responsabilidad de Sano. En su marco feminista es inaceptable ser posicionada como un accesorio de sus propias acciones, y no como alguien con la capacidad de actuar en su propio bien; $y$ ella no está dispuesta a aceptar tal posicionamiento. Su preocupación es sólo en parte por la no intencionada posición de sujeto que las palabras de él aparentemente le han invitado a asumir. Ella cree que el posicionamiento donde él la coloca puede ser indicativo de una actitud general hacia ella, y hacia las mujeres en general, como marginales en lugar de actores centrales en sus propias historias de vida. Ella sabe que él no desea marginar a las mujeres. Cuestiona la posición de sujeto surgida en el habla de él y se resiste a aceptarla. Pero su protesta posiciona a Sano como sexista, un posicionamiento considerado ofensivo por él. Sano rechaza la interpretación de Enferma y la considera como un análisis incorrecto de sus palabras. Esto por supuesto tan sólo tiene sentido en el orden moral de obligaciones interpersonales de él, no en el orden moral feminista. Ambos están comprometidos con la idea preexistente que ellos tenían de sí mismos antes del intercambio. Enferma como feminista y Sano como alguien capaz de cumplir obligaciones sociales. Los dos están también comprometidos a escuchar el intercambio. Las protestas mutuas están dirigidas al sustento de sus definiciones personales y por tanto, tienen una carga emocional muy fuerte.

El episodio pasó a través de un número de ciclos de ofensa recíproca, muy numerosos como para detallarlos aquí. Uno de ellos involucró a Sano acusando a Enferma de usar el peor principio interpretativo, el característico de la respuesta ultrasensible dada por feministas y grupos marginados cuando responden a "situaciones denigratorias". Esto, en opinión de Enferma, es una afirmación de que ella se está haciendo la vida innecesariamente difícil; por eso la gente (incluyendo a Sano) se aleja de ella y de sus opiniones feministas. Esta situación molesta a Enferma mucho más que la 
"disculpa" original, pues se ve a sí misma despojada de toda capacidad para la acción. Además se le considera tonta y como miembro de un grupo marginal que, si se pudiera comportar propiamente, podría equipararse a las personas normales de una sociedad y podría alcanzar el mismo nivel de Sano. Según su protesta original, las palabras de él la habían despojado de su acceso al mundo equitativo, independientemente de si él lo había hecho a propósito o no. Hasta ese punto, según ella había creído, las intenciones de él habían sido buenas, por lo cual ella había considerado importante hablar del tema. Pero él había querido asignarle toda la responsabilidad por la discriminación sufrida por ella. Todo debido a ella y a su manera de ser. Así, la historia continuó con afirmaciones y contraafirmaciones. La complejidad, cuando no la imposibilidad, de "rechazar el discurso" se convirtió en más y más evidente, como lo fue el compromiso subjetivo con los argumentos implícitos con sus implicaciones para el carácter moral de cada uno de los participantes.

Dejando a un lado por un momento los ciclos adicionales ofensivos generados por la conversación original, es posible expresar el episodio de una manera simétrica y en términos de actos de habla y de fuerza ilocucionaria, como sigue:

Us: Siento haberte traído todo este tiempo conmigo, cuando sé que no estás en las mejores condiciones.

Ue: Tú no me trajiste, yo decidí venir contigo.

Llamemos a estas locuciones o acciones de habla Us y Ue respectivamente. Usaremos los símbolos A(Us) y A(Ue) para las acciones de habla que pueden determinarse a través de varios argumentos.

¿Qué actos de habla ocurrieron? Para contestar esta pregunta debemos primero identificar los argumentos donde las locuciones de S y E son momentos. Sólo en relación con estos argumentos las acciones de habla pueden cristalizarse como actos de habla relativamente determinados.

SS Línea de S percibida por S: Tratamiento médico con las posiciones asociadas de $\mathrm{S}=$ Enfermera y $E=$ paciente. En esta historia $A(U s)=$ conmiseración .

SE Argumento de $S$ percibido por E: Paternalismo con las posiciones asociadas de $S=$ hombre independiente y poderoso y $\mathrm{E}=$ mujer dependiente $\mathrm{e}$ indefensa. En esta historia $\mathrm{A}(\mathrm{Us})=$ condescendiente. Ofensa indéxica de S a E.

EE Argumento de E percibido por E: Aventura conjunta con las posiciones asociadas de $\mathrm{S}$ y $\mathrm{E}$ como viajeros en una tierra extraña. En esta historia $\mathrm{A}(\mathrm{Ue})$ es un recordatorio en relación con el argumento.

ES Argumento de E percibido por S: Protesta feminista con las posiciones asociadas de $\mathrm{S}=$ cerdo chovinista y $E=$ feminista intransigente. En esta historia $A(U e)=$ queja. Ofensa indéxica de $E$ a $S$.

La importancia del posicionamiento como un fenómeno real conversacional y no sólo como la herramienta de análisis es evidente en este ejemplo. Dos seres humanos bien dispuestos, de buena fe y de inteligencia razonable al interactuar se vieron atrapados en una discusión engendrada por las propiedades estructurales de la conversación y no por las intenciones de los hablantes. Él no estaba siendo paternalista y ella no se estaba comportando en forma moralista. Sin embargo, cada uno de ellos se dejó llevar por el poder de los argumentos y sus posiciones asociadas, lo cual provocó tales acusaciones mutuas. 
Hay algunos puntos adicionales que deben tomarse en cuenta en relación con este análisis.

Dos personas pueden estar viviendo, sin darse cuenta, narrativas bastante diferentes. En ausencia de cualquier protesta por parte de Enferma, Sano nunca se hubiera cuestionado cómo su posición de persona que da cuidados pudiera haber estado inmersa en el orden moral de alguien cuya posición era radicalmente diferente a la suya. Sin la respuesta particular de ella, él no se hubiera percatado de cuán paternalista podía ser. El silencio de ella pudiera haber sido la confirmación del orden moral de él.

Las palabras por sí mismas no tienen significado. El uso dado por Sano al formato de disculpa es ambiguo. Cuando se coloca en el contexto de la narrativa de Enferma provoca una ofensa indéxica. De manera similar, la protesta de ella al ser considerada "inútil" molesta a Sano, pues en la historia de él, eso va en contra de una ublicua obligación moral.

Hemos mostrado la naturaleza relacional del posicionamiento donde, en el orden moral de Enferma, alguien que toma un argumento responsable puede ubicar a otro como irresponsable. O si uno toma la posición de haber sido agredido por otro, entonces el otro es el perpetrador de la injusticia. Lo obvio y correcto para una persona desde una posición, no es necesariamente así para otra persona en la "otra" posición. La naturaleza relativa del posicionamiento de las personas implica órdenes morales y provoca que la percepción de uno, en la posición relacional, sea casi imposible de entender para el otro.

Las creencias propias acerca de las personas, incluyendo a uno mismo, que están involucradas en una conversación son centrales para como uno entiende lo dicho. La fuerza de cualquier locución en un momento particular dependerá de ese entendimiento.

Al demostrar la naturaleza cambiante de las posiciones, dependiendo de la narrativa, metáforas e imágenes a través de las cuales el posicionamiento se constituye, hemos mostrado cómo el acto social llevado a cabo por la emisión de palabras y el efecto que la acción tiene son una función de las narrativas empleadas por cada hablante, del mismo modo que también es función de las posiciones particulares percibidas por cada hablante.

Hay expectativas normativas en cada nivel. Sano está sorprendido por las protestas de Enferma, porque de acuerdo a las convenciones de la narrativa enfermera-paciente, hay una expectativa normativa donde los débiles necesitan y aceptan cuidado. Esta narrativa, por supuesto, incluye el caso del paciente difícil. Enferma, por su parte, está acostumbrada a ser marginada en el habla de los hombres. Cuando Sano la ofende, lo percibe como inmerso en una conducta masculina normativa. Y por supuesto, dentro de esta narrativa, los hombres son notoriamente incapaces de reconocer que la toma de decisiones paternalistas niega la capacidad de actuar a las mujeres con las cuales están interactuando.

Hemos mostrado que, en el desarrollo de las prácticas discursivas no paternalistas, ni discriminatorias, es necesario separar nuestros significados intencionados y los significados adjudicables, por su efecto. Las implicaciones sociales (personales) de poner atención a las prácticas discursivas a través de las cuales uno se posiciona y es posicionado, se encuentran en el habla cotidiana con sus correspondientes metáforas, imágenes, formas, etcétera y pueden ser reconocidas como inapropiadas desde las creencias políticas/personales de uno y los otros con quienes interactúa. 


\section{Contradicción, elección y posibilidad de actuar}

Los hablantes adquieren creencias acerca de sí mismos. Estas creencias no son necesariamente coherentes y unificadas. Los individuos cambian de una a otra forma de pensar acerca de sí mismos cuando cambia el discurso y cuando toman posiciones dentro de distintos argumentos. Cada una de estas posibles identidades personales puede ser internamente contradictoria consigo misma y con otras posibles identidades localizadas en argumentos diferentes. Como el flujo de eventos pasados, las concepciones mantenidas por los individuos acerca de sí mismos se encuentran dispersas si no se sitúan en una historia. Dado que muchas historias pueden ser dichas, incluso acerca del mismo acontecimiento, cada persona tiene varias identidades coherentes. Pero para actuar racionalmente, esas contradicciones, de las cuales nos damos cuenta inmediatamente, deben remediarse, ser trascendidas, resueltas, o ignoradas. Es lógicamente imposible actuar desde un guión formalmente contradictorio, de la misma forma que nadie podría ir simultáneamente a Boston y a Nueva York. Muchos seres humanos, intencional o no intencionalmente, aceptan que sus creencias acerca de sí mismos y de su ambiente están llenas de contradicciones no resueltas y con las cuales simplemente se vive. Esta característica inherente a una persona viviendo en un universo cristiano era mucho más abiertamente reconocida en el pasado, al pensar en "los caminos insondables de Dios" ¿Cómo podría un Dios benevolente crear un mundo tan injusto? y así sucesivamente. La posibilidad de elegir en una situación con requerimientos contradictorios permite a las personas la posibilidad de actuar voluntariamente ${ }^{3}$.

Cuando elegimos entre demandas contradictorias existe un complejo tejido de posiciones -y significados culturales, sociales y políticos adjudicados a tales posiciones- disponibles dentro de cualquier número de discursos. El significado emocional otorgado a cada una de esas posiciones se desarrolla como resultado de experiencias personales al haber sido colocados en cada posición o habernos relacionado con alguien en esa posición. Esas categorías y emociones adquieren sentido a través de ciertas historias y de un sistema moral que une y legitima la opción elegida.

Debido a la construcción social/gramatical de la persona como una identidad única conocible, tendemos a asumir que es posible haber hecho un conjunto de elecciones consistentes en un solo discurso. $Y$ es verdad, luchamos con diversas experiencias para producir una historia de nosotros mismos que sea unitaria y consistente. Si no lo hiciéramos así, otros nos lo demandarían. También nos producimos a nosotros mismos de manera discursiva, separados del mundo social. Y por ello no somos conscientes de la manera en una u otra práctica discursiva (originada fuera de nosotros) forme nuestro conocer o decir. Experimentamos estas identidades como si fueran enteramente nuestra creación. Tomamos las prácticas discursivas y los argumentos considerándolos nuestros y los entendemos en términos de nuestras propias experiencias particulares. El sentido de continuidad que tenemos en relación a ser una persona particular se compone por una corporeidad continua impregnada de continuidad espacio-temporal y de interpretaciones compartidas de las posiciones del sujeto y de argumentos disponibles. A través de narrativas textuales y vividas se aprende, dentro de una trama consistente, a ser una persona particular, no contradictoria.

${ }^{3}$ ( $\mathrm{N}$ del $\mathrm{T}$ ) "Acting agentically" ha sido traducido como actuar voluntariamente, aunque esta decisión no agota ni expresa todo el significado de "agency". 
En las narrativas feministas, la idea de la persona no contradictoria en un argumento, sin embargo, puede romperse. En el estudio reportado aquí, niños de preescolar con frecuencia trataban de interpretar las narrativas feministas en términos de argumentos más familiares. Una de esas historias era La princesa de la bolsa de papel (Munsch, 1980). En este divertido cuento, una princesa llamada Elizabeth enfrenta peligros increíbles para salvar a su príncipe de un fiero dragón. Al inicio de la historia, la princesa Elizabeth y el príncipe Ronaldo planean casarse, pero un dragón aparece, quema el castillo de Elizabeth y además toda su ropa. Después vuela hacia lo lejos llevándose de los pantalones al príncipe Ronaldo. Elizabeth se enoja. Busca una bolsa de papel para cubrirse y sigue al dragón. Pone trampas para que el dragón agote todos sus poderes mágicos. Finalmente, el dragón es víctima del cansancio y cae en un sueño profundo. Elizabeth entra apresuradamente a la cueva del dragón para salvar a Ronaldo. Pero se lleva una sorpresa: Ronaldo no quiere ser salvado por una princesa sucia y cubierta sólo con una bolsa de papel. Le pide que se vaya y regrese cuando realmente parezca una princesa. Elizabeth se lleva una sorpresa, pero se recupera pronto y dice: "Ronaldo, tu ropa está impecable y tienes un cabello bien cuidado. Pareces príncipe, pero eres un estúpido". La última página muestran a la princesa saltando alegremente sola hacia la puesta de sol. El cuento termina con estas palabras: "Después de todo no se casaron".

Aquí, la intención obvia es presentar una heroína no dependiente del príncipe de sus sueños ni para ser feliz, ni para la confirmación de su identidad. Además, pone en duda el concepto de que el príncipe puede brindar felicidad eterna. En esta historia Elizabeth no es un ser unitario. Experimenta los posicionamientos múltiples y contradictorios que cada ser humano sufre en su vida cotidiana. Se encuentra posicionada al principio como una princesa amorosa, alegre y sin complicaciones, viviendo la narrativa del amor romántico y de la felicidad eterna. Después, es posicionada como la víctima del dragón, pero ella rechaza esto y se vuelve un agente activo, heroico, que controla el flujo de acontecimientos. Ronaldo la posiciona otra vez como víctima y nuevamente rehúsa este posicionamiento. Lo deja, sale de la cueva y salta hacia la puesta de sol. Es libre.

Cuando el dragón quema el castillo de Elizabeth y se roba al príncipe Ronaldo, también quema su ropa y la hace lucir muy sucia. Muchos niños ven este punto como el cambio mágico de una princesa buena a una princesa mala, como si el dragón le hubiera hecho un hechizo. Esa maldad, debida a su desnudez, tiene connotaciones sexuales negativas. Algunos de los niños están entusiasmados por su desnudez y su impotencia, pero generalmente no es Elizabeth quien mantiene tanto su interés, sino el dragón grande, poderoso y destructivo que ha devastado su castillo y después se apresura a devastar los paisajes. Otros niños perciben a Ronaldo como un héroe. Les llama la atención su uniforme de tenista y la medalla que cuelga de su cuello la cual, según lo interpretan, probablemente fue ganada en el deporte. Uno de los niños incluso vio a Ronaldo como heroico, como el agente central en control de su propio destino. Cuando Ronaldo iba en el aire, sostenido de los pantalones por el dragón, el niño expresó con admiración: "Me da gusto que haya agarrado su raqueta de tenis con tanta fuerza. Cuando has hecho eso, bueno, sólo tienes que aferrarte a ella y el dragón te sostiene".

Muchos niños no fueron capaces de ver a Elizabeth como una heroína auténtica. Tampoco pudieron considerar como legítima o positiva su elección de irse sola al final. Para algunos, el dragón es la masculinidad poderosa, cuyo poder permanece intacto a pesar de las trampas ideadas por Elizabeth. En esta interpretación de la historia, Elizabeth claramente pierde a su príncipe no por decisión propia, sino porque no es virtuosa. Muchos niños consideraron que Elizabeth debía haberse bañado primero para poder casarse con el príncipe. Quienes no ven a Elizabeth como heroína, interpretan la historia 
como una variación de una historia conocida donde los hombres son los héroes y las mujeres son solo otras para esos héroes. Elizabeth entonces se convierte en una princesa "normal" (unitaria, no contradictoria) a quien las cosas le salieron un poco mal.

Si Elizabeth es interpretada como princesa, es decir, en el rol de princesa, esta interpretación no feminista sigue de la imagen del rol de princesa. Al abrir con la oración "Elizabeth era una hermosa princesa" el texto sin advertirlo invita a tal interpretación. La única clave de que no es el tipo normal de princesa se encuentra en la primera página del texto al referirse al castillo como "de ella". De acuerdo a la interpretación no feminista, el dragón convierte a Elizabeth en una princesa sucia y mala. (Al ser la magia unitaria y no contradictoria, es necesario lograr ese cambio en ella). Cuando Ronaldo le recomienda un baño, le está dando la información necesaria para regresar a ser una princesa "real", es decir, para romper el hechizo mágico. En la interpretación feminista el rol de princesa no es una categoría interpretativamente dominante. Mas bien, Elizabeth -como la mujer moderna- se encuentra entrampada en un conjunto cambiante de posibilidades, a veces posicionada como alguien con poder, luego como impotente. Elizabeth elige entre las diferentes posiciones de sujeto disponibles para ella y finalmente se escapa de todas.

La reacción de los niños ante esta historia ilustra muchos de los puntos formulados anteriormente. En particular, muestra las múltiples y posibles interpretaciones de cualquier acción de habla, la naturaleza interactiva del movimiento de las palabras habladas (en este caso, las palabras en la página) hacia el acto social que se toma como ocurrido, y la relación íntima entre la percepción de las posiciones en las cuales los distintos personajes se encuentran a sí mismos y la percepción del argumento. Se indica además cómo Elizabeth a veces actúa apropiadamente y en otros casos adopta una conducta tonta. La producción discursiva de uno mismo u otro, como un agente, requiere un argumento apropiado. $\mathrm{Y}$ a las mujeres atrapadas en roles tradicionales, la disponibilidad de prácticas discursivas les permite ser vistas no solamente en un rol fijo. Todos los niños que dieron una interpretación no feminista ilustran la persistencia de prácticas discursivas tradicionales a través de las cuales las acciones se interpretan como actos basados en el género. De esta manera, usar posición en vez de rol es analítica y políticamente necesario al estudiar a la gente en sus mundos cotidianos contemporáneos.

\section{Conclusión}

Al descartar el uso de rol y adoptar el de posición como el concepto central para organizar el análisis de la forma en que la gente se convierte en personas, se ha adoptado otro punto de vista para analizar la relación entre los individuos y sus conversaciones. En la teoría del rol, la persona es siempre separable de los roles diversos que toma; cualquier conversación particular se entiende en términos de las exigencias del rol. Las palabras son en algún grado dictadas por el rol y son interpretadas en estos términos. Con el posicionamiento, el enfoque se dirige a la manera en que las prácticas discursivas constituyen a los hablantes y a los escuchas; al mismo tiempo, es un recurso a través del cual ambos pueden negociar nuevas posiciones. Una posición de sujeto es una posibilidad entre las formas de habla conocidas; la posición es creada, y a través del habla, los hablantes y escuchas se consideran a sí mismos como personas. Esta manera de pensar explica las discontinuidades en la producción de la identidad con referencia a las prácticas discursivas múltiples y contradictorias; explica también las interpretaciones que esas prácticas pueden hacer surgir cuando los participantes se involucran en las conversaciones 


\section{Referencias}

Austin J. L. (1975). How to do things with words (second edition). J.O. Urmson and M. Sbisn (Eds) Oxford, Clarendon Press.

Brownstein R. (1984). Becoming a heroine. Reading about women in novels. Harmondsworth: Penguin.

Coppierters, F. (1981). Social psychology and improvised theatre. University of Antwerp doctoral dissertation

Davies, B. (1982). Life in the classroom and playground. The accounts of primary school children. London: Routledge and Kegan Paul.

Davies, B. (1989). Frogs and snails and feminist tales. Preschool children and gender. Sydney. Allen and Unwin.

Frazer, L. (1990). 'Feminist talk and talking about feminism'. Oxford Review of Education, 15 (2)

Garfinkel, H. (1989) A Manual for the Study of the Naturally Organized Ordinary Activities, Routledge and Kegan Paul , Londres, 3 Vols

Goffman, E. (1974). Frame Analysis. New York: Harper and Row.

Goffman, E. (1981). Forms of Talk. Oxford: Blackwell.

Harre, R. (1979). Social Being. Oxford: Blackwell.

Harre, R. (1983). Personal Being. Oxford: Blackwell.

Harre, R. \& Secord, P.F. (1973). The explanation of social behaviour. Oxford: Blackwell.

Harris, R. (1982). The language makers. London: Duckworth.

Haug, F. (1987). Female sexualisation. London: Verso.

Henriques, J. et al. (1984) Changing the subject. Psychology, social regulation and subjectivity. London, Methuen.

Muhlhausler, P. and Harre, R. (1990). Pronouns and People. Oxford, Blackwell.

Munsch, R. (1980). The Paperbag Princess. Toronto, Annick Press.

Pearce, W. B. (1989) Communication and the Human Conditions. Southern Illinois University

Pearce, W. B. \& Cronen, V. (1981). Communication, action and meaning. New York: Praeger.

Potter, J. and Wetherell, M. (1988). Social psychology and discourse. London: Routledge.

Searle, J. R. (1979). Expression and Meaning. Cambridge, Cambridge University Press.

Smith, P. (1988). Discerning the subject. Minneapolis: University of Minnesota Press.

Strawson, P. F. (1956). Individuals. London, Methuen. 
Weedon, C. (1987). Feminist practice and poststructuralist theory. Oxford: Blackwell.

Zipes, J. (1986). Don't Bet on the Prince. Aldershot, Gower.

\section{Formato de citación}

Davies, Brownyn y Harré, Rom (2007). Posicionamiento: La producción discursiva de la identidad. Traducción de César Cisnero. Athenea Digital, 12, 242-259. Disponible en http://psicologiasocial.uab.es/athenea/index.php/atheneaDigital/article/view/f.

\section{SOMERIGHIS RESERVED}

Este texto está protegido por una licencia Creative Commons.

Usted es libre de copiar, distribuir y comunicar públicamente la obra bajo las siguientes condiciones:

Reconocimiento: Debe reconocer y citar al autor original.

No comercial. No puede utilizar esta obra para fines comerciales.

Sin obras derivadas. No se puede alterar, transformar, o generar una obra derivada a partir de esta obra.

$\underline{\text { Resumen de licencia }}$

$\underline{\text { Texto completo de la licencia }}$ 